\title{
Body Mass Index and Smoking Status as Predictors of Progression to Surgery and Complications and Postoperative Pain in Non-traumatic Back Pain Patients
}

\author{
KR Chin ${ }^{1,2,3,4}$, AY Jorgensen ${ }^{4}$, JR Eiszner ${ }^{4}$, FJR Pencle ${ }^{5}$
}

\begin{abstract}
Objective: While the adverse effects of both smoking and obesity on health are well established, the relationship of smoking and obesity to poor outcomes in specific surgical procedures are less well studied. The aim of this study was to quantify the risks of smoking and obesity in patients who are presenting to spine surgeons for evaluation of non-traumatic back pain.

Methods: This was a retrospective review of prospectively collected data of patients with nontraumatic back pain who presented to a spine surgeon in an academic tertiary referral setting. There were three binary dependent variables: the patient had surgery (yes/no), the patient had postoperative pain (yes/no) and the patient had complications (yes/no). All other variables were considered independent. First, we examined 367 patients (Group 1) presenting for non-traumatic back pain. Next, we examined the subset of 185 patients (Group 2) who proceeded to surgery.

Results: The final logistic model predicting progression to surgery included the variable smoking status. The odds ratio for proceeding to surgery in Group 1 of a smoker versus non-smoker was $O R=2.47(\mathrm{p}<0.01,95 \%$ confidence interval $=1.60,3.81)$. For the patients who had undergone surgery (Group 2), separate logistic models were created to predict complications and pain. The odds ratio for complications: with each increase in body mass index (BMI) of $5 \mathrm{~kg} / \mathrm{m}^{2} \mathrm{OR}=1.41$, $(\mathrm{p}<0.01,95 \%$ confidence interval $=1.11,1.80)$; with positive smoking status OR $=4.85,(\mathrm{p}<$ $0.01,95 \%$ confidence interval $=2.32,10.15$ ). The odds ratio for postoperative pain with each increase in BMI of $5 \mathrm{~kg} / \mathrm{m}^{2}$ was OR $=1.95(\mathrm{p}<0.01,95 \%$ confidence interval $=1.47,2.59)$.

Conclusion: Smokers who presented to our clinic with non-traumatic back pain are more likely to receive a surgical intervention than non-smokers. In patients who undergo surgery, both increased BMI and positive smoking status are associated with a greater likelihood of complications. Body mass index alone, but not smoking status, is associated with a greater likelihood of postoperative pain.
\end{abstract}

Keywords: Body mass index, complications, non-traumatic back pain, predictors of progression to surgery, postoperative pain, smoking

\section{El índice de masa corporal y el hábito de fumar como predictores de la progresión hacia la cirugía, las complicaciones y el dolor postoperatorio en pacientes con dolor de espalda no traumático}

KR Chin ${ }^{1,2,3,4}$, AY Jorgensen ${ }^{4}$, JR Eiszner ${ }^{4}$, FJR Pencle ${ }^{5}$

RESUMEN

Objetivo: Si bien los efectos adversos del tabaquismo y la obesidad sobre la salud están bien deter-

From: ${ }^{1}$ Charles E. Schmidt College of Medicine at Florida Atlantic University, USA, ${ }^{2}$ Herbert Wertheim College of Medicine at Florida International University, USA, ${ }^{3}$ Less Exposure Surgery Specialists Institute (LESS Institute), USA, ${ }^{4}$ University of Pennsylvania School of Medicine, USA and ${ }^{5}$ Less Exposure Surgery (LES)
Society, USA.

Correspondence: Dr K Chin, Less Exposure Surgery Specialists Institute (LESS Institute), 1100 W. Oakland Park Blvd. Suite \#3, Fort Lauderdale, FL, 33311, USA. Email: kingsleychin@thelessinstitute.com 
minados, la relación del hábito de fumar y la obesidad en relación con pobres resultados en procedimientos quirúrgicos especificos, no han sido bien estudiados en la misma medida. El objetivo de este estudio fue cuantificar los riesgos del hábito de fumar y la obesidad en los pacientes que acuden a los cirujanos de columna vertebral para una evaluación de dolor de espalada no traumático. Métodos: Se realizó una revisión retrospectiva de los datos recogidos prospectivamente de pacientes con dolor de espalda no traumático, que acudieron a un cirujano de columna vertebral en un contexto de remisión terciaria académica. Hubo tres variables dependientes binarias: el paciente tuvo cirugía (sí/no), el paciente tuvo dolor postoperatorio (síno), y el paciente tuvo complicaciones (síno). Todas las otras variables fueron consideradas independientes. En primer lugar, examinamos a 367 pacientes (Grupo 1) con dolor de espalda no traumático. A continuación, examinamos el subconjunto de los 185 pacientes (Grupo 2) que procedió a la cirugía.

Resultados: El modelo logístico final que predice el paso a la cirugía. incluye el estado de la variable fumar. El odds ratio para proceder a la cirugía en el grupo 1 de fumadores versus no fumadores fue OR $=2.47(\mathrm{p}<0.01$, el intervalo de confianza 95\% $=1.60,3.81)$. Para los pacientes que habían experimentado cirugía (Grupo 2), distintos modelos logísticos fueron creados para predecir complicaciones y dolor. El odds-ratio de las complicaciones: con cada aumento del indice de masa corporal (IMC) de $5 \mathrm{~kg} / \mathrm{m}^{2}$ OR $=1.41$, (p < 0.01, el intervalo de confianza 95\% =1.11, 1.80); con estatus de tabaquismo positivo $O R=4.85$, $(\mathrm{p}<0.01$, intervalo de confianza 95\% $=2.32,10.15)$. El odds ratio para el dolor postoperatorio con cada aumento del IMC fue $5 \mathrm{~kg} / \mathrm{m}^{2}$ fue OR $=1.95$ (p $<0.01$, intervalo de confianza $95 \%=1.47,2.59$ ).

Conclusión: Los fumadores que acudieron a nuestra clínica con dolor de espalda no traumático, tienen más probabilidades de recibir una intervención quirúrgica que los no fumadores. En los pacientes que se someten a cirugía, tanto un mayor IMC como la condición de ser fumador están asociados con una mayor probabilidad de complicaciones. El indice de masa corporal solo, sin la condición de fumador, se halla asociado con una mayor probabilidad de dolor postoperatorio.

Palabras claves: índice de masa corporal, complicaciones, dolor de espalda no traumático, predictores de progresión a la cirugía, dolor postoperatorio, hábito de fumar

\section{West Indian Med J 2017; 66 (3): 410}

\section{INTRODUCTION}

Clinical studies suggest the association between smoking and worse outcomes in spine surgery. A case-control study of 214 patients with proven intervertebral disc herniation showed increased rates of smoking in the subset of patients $\leq 35$ years old compared to controls (1). In a series of 195 patients undergoing lumbar interbody fusion, smoking was associated with reduced rates of fusion maintenance (2). In a series of 426 patients who underwent lumbar spinal fusion procedures, smoking was associated with higher rates of non-union (3). There seems to be consensus that smoking leads to poorer outcomes in spine surgery.

The literature regarding associations between obesity and spine surgery outcomes is more contradictory. An analysis of outcomes in 86 patients undergoing repair of a pseudarthrosis that had developed following a localized lumbar arthrodesis failed to find statistically significant associations involving obesity, although smoking was associated with poorer outcomes (4). A prospective study of 609 neurosurgical patients found a strong association between obesity and surgical site infections (5), a similar conclusion was reached in a retrospective case-control study of 219 patients who had undergone laminectomy or spinal fusion (6) and by a retrospective survey of 850 spinal procedures (7). The authors of a study that reviewed a series of 298 elderly patients of varying BMI who had undergone lumbar spinal surgeries concluded that obesity was not associated with higher complication rates but did find higher rates of patient dissatisfaction in the obese (8). In contrast, the authors of a review of 3289 surgically treated lumbar disc herniation patients found that obesity was associated with higher rates of complications (9). Finally, a prospective study of 252 patients undergoing posterior thoracolumbar spine surgery found that the obese had significantly higher rates of postoperative meralgia paresthetica (10). Further work needs to be done to clarify the relationship between obesity and outcomes in spine surgery.

This study represents an effort to delineate the effects of smoking and in particular obesity on complications and postoperative pain rates in patients with non-traumatic back pain in a quantitative manner that can be used to predict outcomes in clinical practice.

\section{SUBJECTS AND METHODS}

The charts of all patients presenting to the orthopaedic spine clinic at a major academic teaching hospital were reviewed between 2003 and 2005. Institutional review board approval was granted for this study and collection period. Of those charts, 395 patients were identified with the chief complaint of 
non-traumatic back pain. Further chart review documented age, gender, smoking status, BMI, surgery, postoperative pain and complications from 367 out of the original 395 charts. The 28 excluded charts had evidence of trauma. Those 367 data points represented the initial study group used to determine predictors of progression to surgery (Group 1). Of the patients in Group 1, a subset of 185 patients had surgery and was used to evaluate predictors of complications and postoperative pain (Group 2).

The analysis considered age and BMI as continuous variables. Gender, smoking status, surgery, postoperative pain and complications were considered as binary variables. Smokers were defined as those currently smoking or those who had quit within the last 10 years. Non-smokers were those who had never smoked or quit more than 10 years ago. The particular surgical procedure was not considered as a variable, only whether or not surgery occurred. These procedures included but were not limited to cervical fusions, corpectomies and lumbar decompressions with or without fusion. Complications were not stratified by type, only the presence or absence of a complication was considered in the analysis. Likewise for pain, it too was considered as binary only. A complication can be defined as any deviation from the ideal postoperative course that is not inherent in the procedure and does not comprise a failure to cure (11). Subjective evaluation of pain was recorded using a numeric rating scale.

\section{Variable selection and modelling}

All the data points and associated variables were read into SAS Version 9 software. The SAS logistic procedure was used on both Groups 1 and 2 to create maximum likelihood estimation logistic regression models under the assumption of linearity in the logit. Surgery (yes/no), complications (yes/no) and postoperative pain (yes/no) were the dependent variables modelled with the rest as independents. Independent variable determination was done by an examination of the Wald test statistics for the full multivariate models and univariate models. With one exception, the criterion for inclusion of a variable was $\alpha=0.05$. The likelihood ratio test was used to compare the final main effects models to the full multivariate models to confirm that the independent variables rejected were not significant.

Once main effects determination was complete, the authors' clinical experience was used to determine which interaction effects to consider. For example, an interaction effect between age and gender was not tested as there seems to be no reason to suspect such an interaction. Interaction effects between smoking and BMI were examined for significance using the likelihood ratio test as it seems plausible those two effects might interact.

The Hosmer and Lemeshow test was performed on all final models to check for a fit between the predicted probabilities of the dependent variables to the observed probabilities. As a way of visualizing the value of the models to predict outcomes in clinical practice, sensitivity and specificity versus cut-point were plotted. Receiver operating characteristics (ROC) curves and areas were also calculated.

\section{RESULTS}

\section{Demographics}

The complete set of 367 patients (Group 1) comprised 161 males and 206 females with ages ranging from 18-96 years and averaged 49.8 years. Body mass index ranged from $17.4 \mathrm{~kg} / \mathrm{m}^{2}$ to $64.6 \mathrm{~kg} / \mathrm{m}^{2}$ and averaged $29.6 \mathrm{~kg} / \mathrm{m}^{2}$. There were 155 smokers and 212 non-smokers. The subset of 185 patients (Group 2) progressed to surgery; 66 of whom had postoperative pain and 57 had complications.

\section{Progression to surgery}

This analysis was performed in Group 1 with 367 patients. Stratification of the patients by age, smoking status and surgery is shown in Table 1 and in Fig. 1. Model development with Wald test statistics is indicated in Table 2.

Table 1: Classification of Group 1 patients by age, smoking status and surgery

\begin{tabular}{lccccc}
\hline $\begin{array}{c}\text { Age } \\
\text { (years) }\end{array}$ & \multicolumn{2}{c}{ Non-smokers } & \multicolumn{3}{c}{ Smoker } \\
\hline 18 to 19 & 3 & 0 & 2 & 2 & 7 \\
20 to 29 & 8 & 9 & 1 & 3 & 21 \\
30 to 39 & 11 & 12 & 14 & 25 & 62 \\
40 to 49 & 33 & 22 & 15 & 38 & 108 \\
50 to 59 & 29 & 19 & 9 & 13 & 70 \\
60 to 69 & 20 & 15 & 13 & 14 & 62 \\
70 to 79 & 15 & 7 & 2 & 3 & 27 \\
80 to 89 & 7 & 1 & 0 & 1 & 9 \\
90 to 96 & 0 & 1 & 0 & 0 & 1 \\
\hline Total & $\mathbf{1 2 6}$ & $\mathbf{8 6}$ & $\mathbf{5 6}$ & $\mathbf{9 9}$ & $\mathbf{3 6 7}$ \\
\hline
\end{tabular}

Classification of Patients by Age, Smoking Status, and Surgery

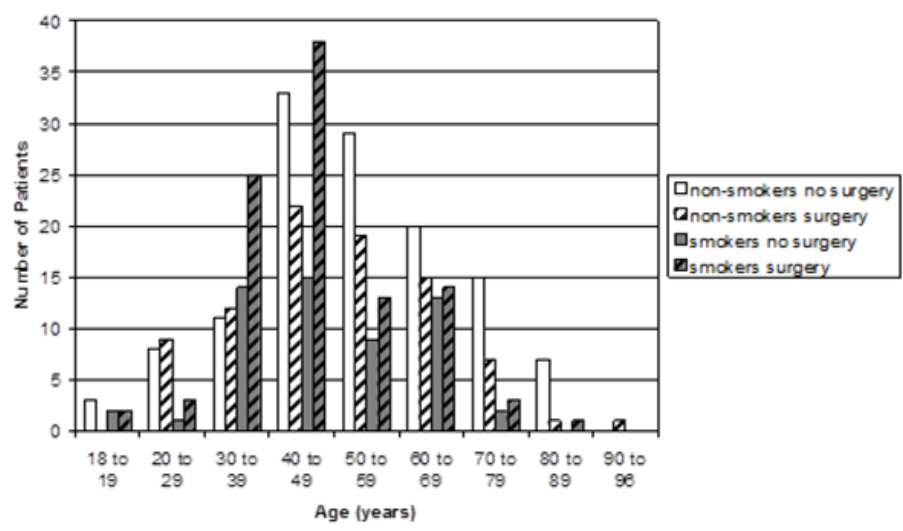

Fig. 1: Stratification of Group 1 patients by age, smoking status and surgery.

Table 2: Surgery probability logistic regression models Wald statistics

\begin{tabular}{lcc}
\hline Variable & Full multivariable model & Univariable model \\
\hline Age & $p=0.11$ & $p=0.04$ \\
BMI & $p=0.28$ & $p=0.41$ \\
Gender & $p=0.73$ & $p=0.86$ \\
Smoking status & $p<0.01$ & $p<0.01$ \\
\hline
\end{tabular}

BMI: body mass index 
On the basis of Wald statistics, gender $(p=0.73)$ and BMI ( $p=0.28)$ were quickly rejected from the final model. In the full multivariate model, the age Wald statistic has a $p=0.11$, not meeting the criterion for $\alpha$. When the Wald test was performed on the univariate age model for surgery progression, the $p$-value decreased to 0.04 . This is suggestive of a correlation between age and the only other independent variable, smoking status. For this reason, the final main effects model included, both age and smoking status as significant independent variables while discarding BMI and gender. In fact, a comparison of the final model to a univariate smoking status model shows the odds ratio for smoking is reduced in the model containing age.

Interaction effects were considered in two ways. The full multivariate model was compared to a full model with a $\mathrm{BMI} / \mathrm{smoking}$ interaction. The likelihood ratio test with one degree of freedom resulted in $p=0.49$, which did not support the BMI/smoking interaction. The final main effects model was also compared to a final main effects model with an age/ smoking interaction. The likelihood ratio test yielded $p=0.86$, again not supporting the significance of interaction effects.

The predictions of the final main effects model for progression to surgery are plotted with $95 \%$ confidence bands in Fig. 2.

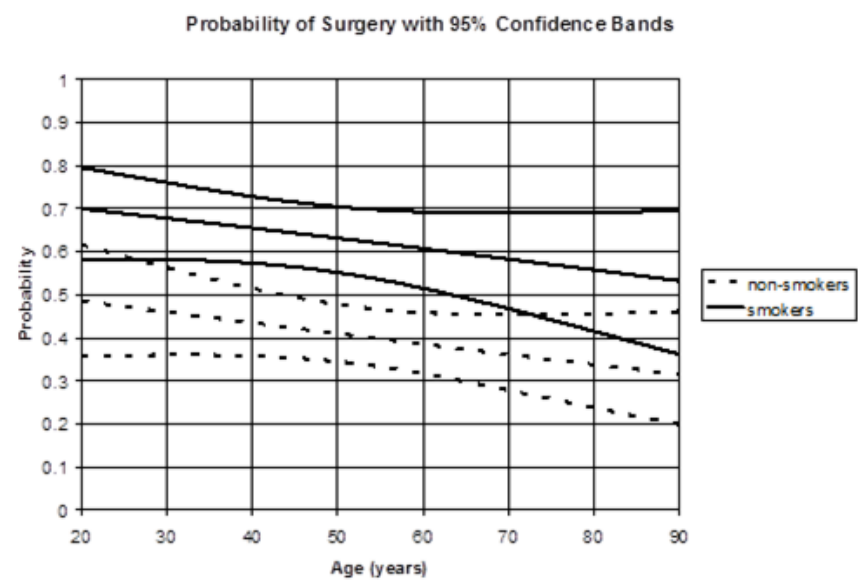

Fig. 2: Graphical view of Group 1 surgery probability as a function of age and smoking status including $95 \%$ confidence bands.

Non-smoking and smoking predictions are overlaid. Final odds ratios for proceeding to surgery: smoker versus non-smoker OR $=2.47(p<0.01,95 \%$ confidence interval $=$ $1.60,3.81) ; 10$ year increase in age $\mathrm{OR}=0.90(p=0.16$, $95 \%$ confidence interval $=0.78,1.04)$. The Hosmer and Lemeshow test on the final main effects model had a $\chi^{2}=7.09$ with eight degrees of freedom corresponding to $p=0.53$, indicating a reasonable fit of the predicted probabilities to the observed probabilities. Sensitivity and specificity versus cutpoint plot is in Fig. 3. The optimized sensitivity and specificity is shown as $61 \%$. Area under the ROC curve was calculated as 0.63 indicating poor accuracy of the test.

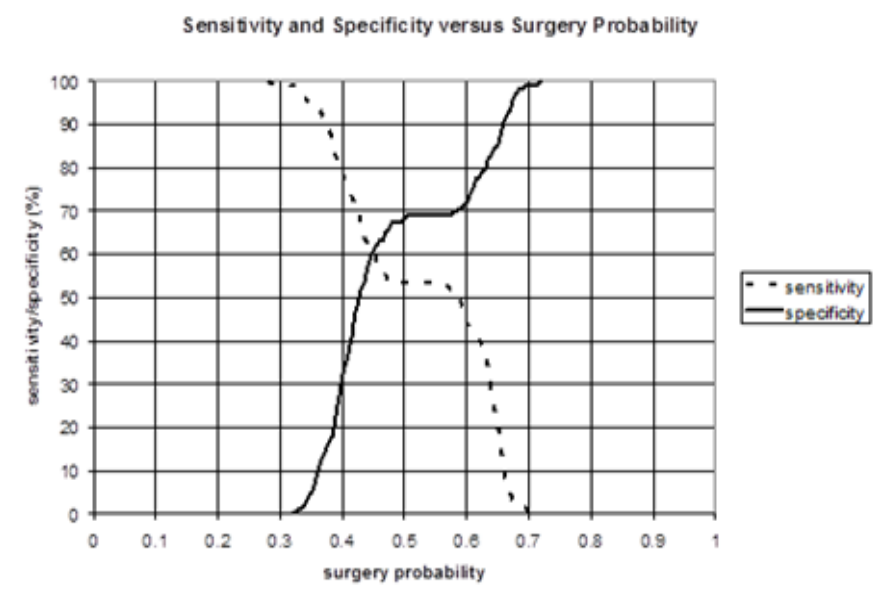

Fig. 3: Group 1 logistic regression model sensitivity and specificity $v s$. surgery probability cut-point. The intersection of the two curves is $61 \%$.

\section{Probability of complications}

Group 2 consists of 185 patients who underwent surgery. Stratification of Group 2 by BMI, smoking status and complications is shown in Table 3. Model development with Wald test statistics is indicated in Table 4.

Table 3: Classification of Group 2 patients by body mass index, smoking status and complications

\begin{tabular}{llllll}
\hline & \multicolumn{2}{c}{ Non-smokers } & \multicolumn{2}{c}{ Smoker } \\
BMI & No comp. & Comp. & No comp. & Comp. & Total \\
\hline 19 to 20 & 2 & 0 & 0 & 0 & 2 \\
21 to 25 & 22 & 3 & 13 & 8 & 46 \\
26 to 30 & 21 & 6 & 28 & 11 & 66 \\
31 to 35 & 17 & 0 & 8 & 12 & 37 \\
36 to 40 & 6 & 1 & 5 & 8 & 20 \\
41 to 45 & 3 & 1 & 0 & 3 & 7 \\
46 to 50 & 1 & 1 & 1 & 1 & 4 \\
51 to 55 & 0 & 1 & 0 & 1 & 2 \\
55 to 60 & 0 & 0 & 0 & 0 & 0 \\
61 to 65 & 1 & 0 & 0 & 0 & 1 \\
\hline Total & 73 & 13 & 55 & 44 & 185 \\
\hline BMI: body mass index; comp: complication \\
Comp: Complication
\end{tabular}

Table 4: Complication probability logistic regression models Wald statistics

\begin{tabular}{lcc}
\hline Variable & Full multivariable model & Univariable model \\
\hline Age & $p=0.66$ & $p=0.51$ \\
BMI & $p<0.01$ & $p<0.01$ \\
Gender & $p=0.74$ & $p=0.81$ \\
Smoking status & $p<0.01$ & $p<0.01$ \\
\hline
\end{tabular}

BMI: body mass index

On the basis of Wald statistics, age $(p=0.66)$ and gender $(p=$ $0.74)$ were quickly rejected from the final model. Both BMI $(p<0.01)$ and smoking status $(p<0.01)$ meet the criterion for $\alpha$. For this reason, the final main effects model included both BMI and smoking status as significant independent variables while discarding age and gender.

An interaction effect was considered. The final main effects model was compared to a final main effects model with a $\mathrm{BMI} /$ smoking interaction. The likelihood ratio test yielded $p=0.34$, which did not support the significance of interaction. 
The predictions of the final main effects model for complications are plotted with 95\% confidence bands in Fig. 4, non-smoking and smoking predictions are overlaid.

Probability of Complications with $95 \%$ Confidence Bands

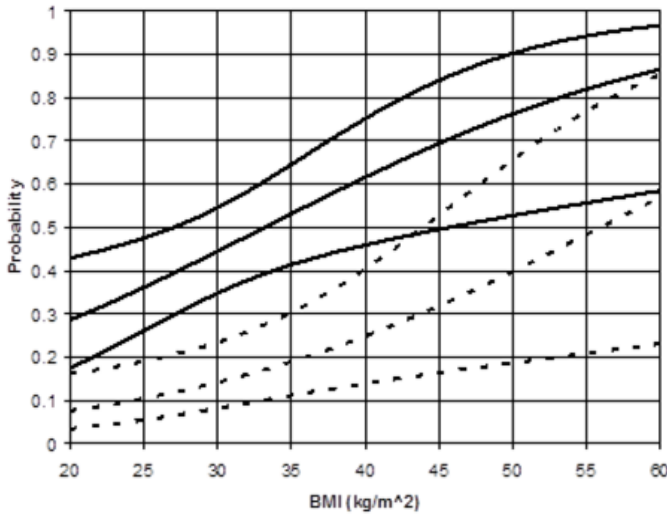

- non-s mokers - smokers

Fig. 4: Graphical view of Group 2 complications probability as a function of body mass index and smoking status with $95 \%$ confidence bands.

Final odds ratios for complications: with each increase in BMI of $5 \mathrm{~kg} / \mathrm{m}^{2} \mathrm{OR}=1.41(p<0.01,95 \%$ confidence interval $=1.11,1.80)$; smoker versus non-smoker $\mathrm{OR}=4.85(p<$ $0.01,95 \%$ confidence interval $=2.32,10.15$ ). The Hosmer and Lemeshow test on the final main effects model had a $\chi^{2}=$ 11.50 with eight degrees of freedom corresponding to $p=$ 0.18 . Sensitivity and specificity versus cut-point plot is in Fig. 5. The optimized sensitivity and specificity is shown as $63 \%$. Area under the ROC curve was calculated as 0.73 indicating fair accuracy.

Sensitivity and Specificity versus Complications Probability

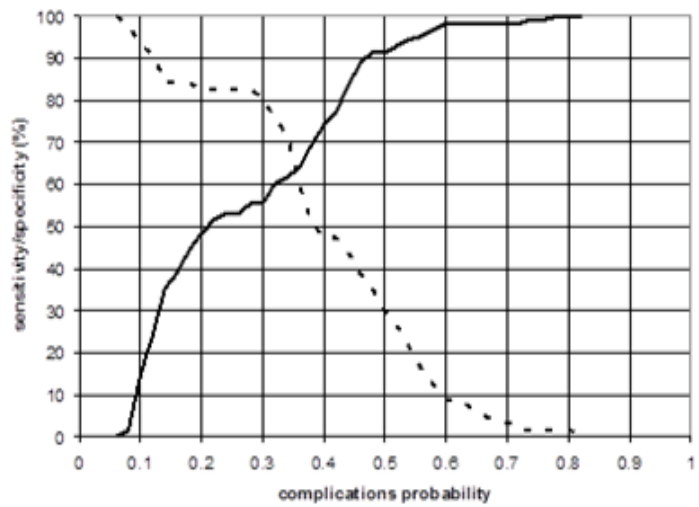

- - sensitivity

Fig. 5: Group 2 logistic regression model sensitivity and specificity vs complications probability cut-point. The intersection of two curves is $3 \%$

\section{Probability of postoperative pain}

Group 2 analysis was repeated with the dependent variable postoperative pain. Stratification of Group 2 by BMI, smoking status and postoperative pain is shown in Table 5. Model development with Wald test statistics is indicated in Table 6 .
Table 5: Classification of Group 2 patients by body mass index, smoking status and pain

\begin{tabular}{lccccc}
\hline \multirow{2}{*}{ BMI } & \multicolumn{2}{c}{ Non-smokers } & \multicolumn{3}{c}{ Smoker } \\
No comp. & Comp. & No comp. & Comp. & Total \\
\hline 19 to 20 & 2 & 0 & 0 & 0 & 2 \\
20 to 25 & 20 & 5 & 19 & 2 & 46 \\
25 to 30 & 21 & 6 & 28 & 11 & 66 \\
$30-35$ & 11 & 6 & 5 & 15 & 37 \\
35 to 40 & 3 & 4 & 7 & 6 & 20 \\
40 to 45 & 1 & 3 & 0 & 3 & 7 \\
45 to 50 & 0 & 2 & 1 & 1 & 4 \\
50 to 55 & 1 & 0 & 0 & 1 & 2 \\
55 to 60 & 0 & 0 & 0 & 0 & 0 \\
60 to 65 & 0 & 1 & 0 & 0 & 1 \\
\hline Total & $\mathbf{7 3}$ & $\mathbf{1 3}$ & $\mathbf{5 5}$ & $\mathbf{4 4}$ & $\mathbf{1 8 5}$ \\
\hline BMI: $b 0$ & &
\end{tabular}

BMI: body mass index; comp: complication

Comp: Complication

Table 6: Pain probability logistic regression models Wald statistics

\begin{tabular}{lcc}
\hline Variable & Full multivariable model & Univariable model \\
\hline Age & $p=0.84$ & $p=0.60$ \\
BMI & $p<0.01$ & $p<0.01$ \\
Gender & $p=0.91$ & $p=0.49$ \\
Smoking status & $p=0.29$ & $p=0.26$ \\
\hline
\end{tabular}

BMI: body mass index

On the basis of Wald statistics, age $(p=0.84)$ and gender $(p=0.91)$ were quickly rejected from the final model. In the univariate smoking model, the BMI and smoking model, and the full multivariate model, the $p$-value for smoking status ranged between 0.26 and 0.29 . For this reason, smoking status was rejected from the final model. Body mass index $(p<0.01)$ met the criterion for $\alpha$. The final main effects model included only BMI as a significant independent variable while discarding age, gender and smoking status.

An interaction effect was considered. A BMI and smoking model was compared to itself with a $\mathrm{BMI} /$ smoking interaction. The likelihood ratio test yielded $p=0.55$, which did not support the significance of interaction.

The predictions of the final main effects model for pain are plotted with 95\% confidence bands in Fig. 6 .

Probability of Pain with $95 \%$ Confidence Bands

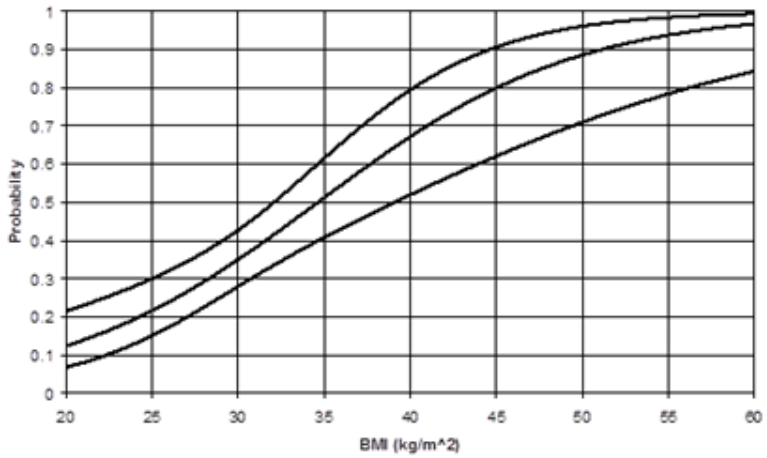

Fig. 6: Graphical view of Group 2 pain probability as a function of body mass index with a $95 \%$ confidence bands. 
The odds ratio for postoperative pain with each increase in BMI of $5 \mathrm{~kg} / \mathrm{m}^{2}$ was $\mathrm{OR}=1.95(p<0.01,95 \%$ confidence interval $=1.47,2.59$ ). The Hosmer and Lemeshow test on the final main effects model had a $\chi^{2}=9.78$ with eight degrees of freedom corresponding to $p=0.28$. Sensitivity and specificity versus cut-point plot is in Fig. 7.

Sensitivity and Specificity versus Pain Probability

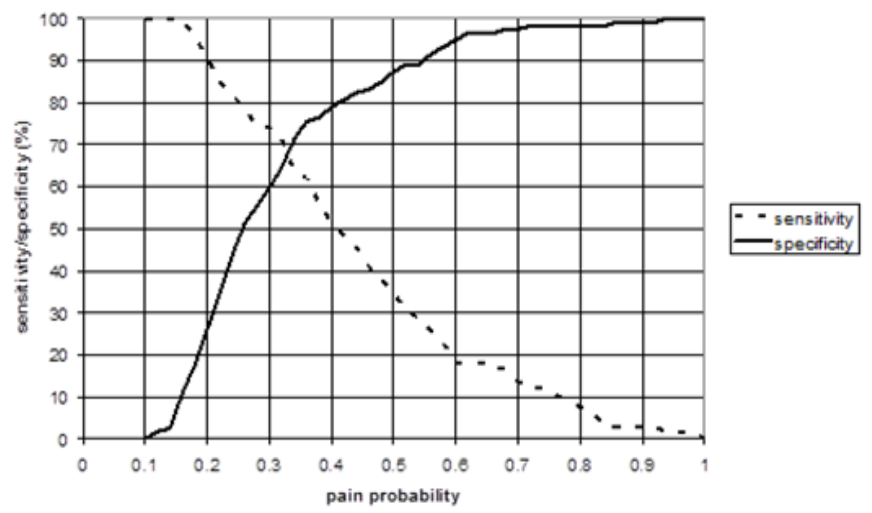

Fig. 7: Group 2 logistic regression model sensitivity and specificity $v s$ pain probability cut-point. The intersection of the two curves is $68 \%$.

The optimized sensitivity and specificity is shown as $68 \%$. Area under the ROC curve was calculated as 0.73 , the same as for the final complications model.

\section{DISCUSSION}

In the population of patients with non-traumatic back pain presenting to spine surgeons at an academic medical centre, this study has demonstrated important associations between BMI, smoking status, progression to surgery, complications and postoperative pain. It has been less successful in defining models that can be used to predict outcomes in a clinical setting.

The analysis supports a statistically significant association between smoking $(p<0.01)$ and increasing likelihood of progressing to surgery after evaluation by a spine surgeon. Smoking has been demonstrated as risk factor for revision surgery in spinal deformity, leading us to conclude it also increases the risk of surgery from the outset (12). After surgery, the results show that both increasing BMI $(p<$ $0.01)$ and smoking $(p<0.01)$ are independently associated with increasing complication rates. Further, an association between increasing BMI $(p<0.01)$ and postoperative pain was demonstrated. Interaction effects between obesity and smoking were also examined using the likelihood ratio test to see if they improved the logistic regression models. For all three models; progression to surgery, complications and postoperative pain, the inclusion of interactions were found not to improve the models.

This study attempted to demonstrate the utility of logistic regression models to predict surgery progression, compliplications and postoperative pain. The model for progression to surgery was able to achieve an optimized sensitivity and specificity of only approximately $61 \%$. The area under the ROC was a disappointing 0.63 . The models for complications and postoperative pain faired somewhat better, both achieving optimized sensitivities and specificities of $63 \%$ and $68 \%$, respectively, as well as areas under the ROC of 0.73 each. The logistic regression models are not powerful predictors of individual patient outcomes. They are far more useful in demonstrating the adverse effects of increased BMI and smoking in the population of patients with non-traumatic back pain, as opposed to the individual patient.

Most studies in the literature do a good job of determining the statistical significance of associations (13-21), but do not extend the analysis further to attempt to predict outcomes for individual patients. This study extend that analysis and, while the sensitivities and specificities of the models were clearly less than what clinicians would hope for, it provides a direction for future studies to consider more independent variables with the result likely being improved sensitivity and specificity. The present study did not group obesity into ranges but considered obesity as a continuous variable. This is an advantage over most other analyses which have grouped patients into ranges. A significant part of this study population was obese and had a positive smoking history. In consideration of this, the study was designed to allow interaction effects to be tested. In all these ways, the present analysis is unique in the literature.

The present study had limitations. Indications for surgery included failed conservative management; however, additional analysis was not performed on each indication such as pain and neurologic deficits. Different types of surgery and different types of complications were both grouped into single variables. The result was that the study subjects were heterogeneous in ways that were not accounted for in the analysis. Logistic regression works best when used in homogeneous, not heterogeneous, groups. That fact is reflected in the disappointing predictive power of the models derived in this study. Also, of concern is the subjective nature of the patient classification into postoperative pain groups, as well as the dichotomous classification of patients into smoking/non-smoking categories. The analysis would certainly have benefitted if the study subjects' smoking histories were considered as continuous variables in the same way as obesity.

\section{ACKNOWLEDGEMENT'S}

The authors acknowledge the advice and knowledge of J Jon Veloski, Director Medical Education Research, Jefferson Medical College

\section{AUTHORS' NOTES}

Conflicts of interest and sources of funding: We did not seek or receive any funding from the National Institutes of Health (NIH), Wellcome Trust, Howard Hughes Medical Institute (HHMI), or others for this work. KRC, AYJ, JRE and FJRP do not have any potential conflicts of interest to declare for this work. 


\section{REFERENCES}

1. Chang S, Zhou J, Wang D, Liao Q. [Relationship between smoking and drinking and herniation of intervertebral disc]. Hunan yi ke da xue xue bao $=$ Hunan yike daxue xuebao $=$ Bulletin of Hunan Medical University $1999 ; \mathbf{2 4}: 20-2$.

2. Mooney V, McDermott KL, Song J. Effects of smoking and maturation on long-term maintenance of lumbar spinal fusion success. J Spinal Disorders 1999; 12: 380-5.

3. Andersen T, Christensen FB, Laursen M, Hoy K, Hansen ES, Bunger C. Smoking as a predictor of negative outcome in lumbar spinal fusion. Spine 2001; 26: 2623-8.

4. Carpenter CT, Dietz JW, Leung KY, Hanscom DA, Wagner TA. Repair of a pseudarthrosis of the lumbar spine. A functional outcome study. $\mathrm{J}$ Bone Joint Sur Am 1996; 78: 712-20.

5. Cronquist AB, Jakob K, Lai L, Della Latta P, Larson EL. Relationship between skin microbial counts and surgical site infection after neurosurgery. Clin Infect Dis 2001; 33: 1302-8.

6. Olsen MA, Mayfield J, Lauryssen C, Polish LB, Jones M, Vest J et al. Risk factors for surgical site infection in spinal surgery. J Neurosur 2003; 98 (2 Suppl): 149-55.

7. Wimmer C, Gluch H, Franzreb M, Ogon M. Predisposing factors for infection in spine surgery: a survey of 850 spinal procedures. J Spinal Disord 1998; 11: 124-8.

8. Gepstein R, Shabat S, Arinzon ZH, Berner Y, Catz A, Folman Y. Does obesity affect the results of lumbar decompressive spinal surgery in the elderly? Clin Orthopaed Related Res 2004; 138-44.

9. Kardaun JW, White LR, Shaffer WO. Acute complications in patients with surgical treatment of lumbar herniated disc. J Spinal Disord 1990; 3: $30-8$.

10. Yang S-H, Wu C-C, Chen P-Q. Postoperative meralgia paresthetica after posterior spine surgery: incidence, risk factors, and clinical outcomes. Spine 2005; 30: E547-50.

11. Dindo D, Clavien PA. What is a surgical complication? World J Surg 2008; 32: 939-41.

12. Puvanesarajah V, Shen FH, Cancienne JM, Novicoff WM, Jain A, Shimer
AL et al. Risk factors for revision surgery following primary adult spinal deformity surgery in patients 65 years and older. J Neurosurg Spine 2016: $1-8$.

13. Planchard RF, Higgins DM, Mallory GW, Puffer RC, Jacob JT, Curry $\mathrm{TB}$ et al. The Impact of obesity on perioperative resource utilization after elective spine surgery for degenerative disease. Global Spine J 2015; 5: 287-93.

14. Higgins DM, Mallory GW, Planchard R, Puffer R, Ali M, Gates M et al. Understanding the impact of obesity on short-term outcomes and in-hospital costs after instrumented spinal fusion. Neurosurg 2015. Epub 2015/09/10. doi: 10.1227/neu.000000000001018. PubMed PMID: 26352096.

15. De la Garza-Ramos R, Bydon M, Abt NB, Sciubba DM, Wolinsky JP, Bydon A et al. The impact of obesity on short- and long-term outcomes after lumbar fusion. Spine 2015; 40: 56-61.

16. Burks CA, Werner BC, Yang S, Shimer AL. Obesity is associated with an increased rate of incidental durotomy in lumbar spine surgery. Spine 2015; 40: 500-4.

17. Werner BC, Rawles RB, Jobe JT, Chhabra AB, Freilich AM. Obesity is associated with increased postoperative complications after operative management of distal humerus fractures. J Shoulder Elbow Surg 2015; 24: $1602-6$.

18. Seicean A, Seicean S, Alan N, Schiltz NK, Rosenbaum BP, Jones PK et al. Effect of smoking on the perioperative outcomes of patients who undergo elective spine surgery. Spine 2013; 38: 1294-302.

19. Appaduray SP, Lo P. Effects of diabetes and smoking on lumbar spinal surgery outcomes. J Clin Neurosci 2013; 20: 1713-7.

20. Sanden B, Forsth P, Michaelsson K. Smokers show less improvement than nonsmokers two years after surgery for lumbar spinal stenosis: a study of 4555 patients from the Swedish spine register. Spine 2011; 36: 1059-64.

21. Stienen MN, Richter H, Prochnow N, Schnakenburg LF, Gautschi OP. [Does smoking correlate with low back pain and the outcome of spinal surgery?]. Z Orthop Unfall 2011; 149: 317-23. 